\title{
Two case studies on structural variation in multilingual settings
}

\author{
Ariana Bancu*
}

\begin{abstract}
In this article, I report on two analyses of variation in Transylvanian Saxon (TrSax), an endangered Germanic language in contact with German and Romanian, used in settings predictive of structural influences among languages. My goals are to document the structural properties of the target variables and to evaluate if processes of language contact have an effect on synchronic variation in TrSax. I identified two areas of TrSax that display variation at the morphosyntactic level, and in each case one of the variants has a corresponding structure in German, while the other variant has a corresponding structure in Romanian. To tease apart contact-induced variation from internally motivated variation, I compare data from multilingual speakers with different linguistic profiles and assess the effect of sociolinguistic factors on variation through mixed effects analyses. Variation that patterns similarly across these two groups can provide a clearer account of the structure of TrSax, while differences between the groups can shed light on trajectories of change in TrSax. Furthermore, results of this study have implications for borrowing hierarchies in language contact.
\end{abstract}

Keywords. Language contact, morphosyntactic variation, Transylvanian Saxon, verb clusters, category-specific conjunctions

1. Introduction. There is growing interest in explaining synchronic variation in endangered languages by using sociolinguistic analyses as a tool for capturing linguistic structure in the process of language documentation, and for understanding contact-induced language change (cf. Nagy 2017, Meyerhoff 2019). Thus, extending analyses of variation to lesser-studied languages contributes to documenting such languages (cf. Tagliamonte 2017, 2019), and to better understanding the effects of socially dominant languages on the structure of minority languages. In this paper, I report on two case studies on morpho-syntactic variation in Transylvanian Saxon (TrSax), an endangered Germanic language spoken in Romania for the past eight centuries, and, more recently (about 30 years), in diasporic communities in Germany. I take a sociolinguistic approach to analyzing variation, i.e. I establish the distribution of variants for each target variable and the effect of potential linguistic and sociolinguistic factors on variation through mixed effects analyses. In doing so, I show how such methods can be effective in identifying both linguistically motivated variation and contact-induced variation in a lesser-studied language.

As variation and language change are tightly interconnected, structural variation in an endangered language could be an indicator of a contact-induced change in progress, as endangered languages rarely exist in the absence of multilingualism. The social circumstances in an endangerment situation are characterized by uneven social dynamics between speakers of an

\footnotetext{
* I would like to thank the Transylvanian Saxon speakers who shared their language with me, as well as the research assistants who collected, transcribed, translated the data, and provided me with their expertise. This article is based on my dissertation and I would like to thank my committee: Marlyse Baptista, Robin Queen, Acrisio Pires, Sarah Thomason, and Susi Wurmbrand, for their invaluable input. A special thanks also to Lewis Gebhardt for his continued support, and to Northeastern Illinois University for allowing me to take this research on the road. Key aspects of this research were funded by the Department of Linguistics, the Rackham Graduate School, and CREES at the University of Michigan. Author: Ariana Bancu, Northeastern Illinois University (AV-Bancu@neiu.edu).
} 
endangered language (typically a numerically subordinate group) and speakers of a dominant language (a numerically dominant group). Such circumstances lead to an intense contact among the languages that sets the stage for structural influences among the languages involved (O'Shannessy 2011:80).

Therefore, variables that capture the multilingual profiles of the speakers should be included in an analysis of variation in an endangered language to better understand how language contact may affect variation. At the same time, typical sociolinguistic variables (e.g., age, gender, social class) cannot be used to explain how changes percolate in a speech community when there are only a handful of speakers left. Thus, working with lesser-studied languages may pose several challenges, but with methodological adaptations such challenges can be overcome, allowing both sociolinguistic variationists and documentary field linguists to tackle some interesting cases of variation in lesser-studied languages (Mansfield and Stanford 2017).

The goals of my research are to document the structural properties of the two target variables that display variation in TrSax, and to evaluate if processes of language contact have an effect on synchronic variation. TrSax is an outlying dialect of Moselle Franconian, and it is closely related to Luxembourgish and German. TrSax has been in prolonged contact of eight centuries with German and Romanian, each language fulfilling a different role in TrSax communities. Historically, each of the three languages had a specialized function for a communicative sphere in a manner indicative of triglossia (cf. Fishman 1991). TrSax is traditionally seen as the home language and the main language used for communication with members of the TrSax community. TrSax is transmitted orally, it is not written or taught in schools, nor does it have a standardized variety. German is used for literacy purposes and it is viewed as a prestige variety by Transylvanian Saxons. German is an official minority language in Romania available for education, religious purposes, and, to some extent, in the media. Transylvanian Saxons typically receive their education in German and also use it in church. Romanian has been used as a tertiary language for limited communication, TrSax and German fulfilling the major linguistic needs in TrSax communities.

However, more recent events, connected to the revolution in Romania in 1989, reshaped TrSax communities and their linguistic ecologies. A significant number of Transylvanian Saxons migrated from Romania to Germany in the years before and immediately after the revolution, so that there are currently more Transylvanian Saxons living in Germany than in Romania. This led to a more intense contact between TrSax and Romanian in Romania, and TrSax and German in Germany. Currently, speakers of TrSax who grew up in Romania are trilingual ${ }^{1}$, in that they are fluent in German and Romanian as well (whether they live in Germany or Romania). The data analyzed in the two case studies presented here were collected through my own fieldwork in Romania and in Germany, and recorded using sociolinguistic interviews. All speakers interviewed are originally from the village of Viscri, Romania, and use German and Romanian to various degrees. Throughout this article I use the term TrSax when discussing the language more generally, and the term 'Viscri Saxon' when discussing characteristics of the dialect from Viscri'.

\footnotetext{
${ }^{1}$ As I learned from the participants I interviewed for this study, children of first generation TrSax immigrants in Germany do not speak Romanian, and many of them have only passive knowledge of TrSax.

${ }^{2}$ TrSax speakers from Viscri call their dialect Weißkircherisch 'Viscri Saxon'. The speakers I consulted believed that Weißkircherisch is different from TrSax dialects in neighboring villages, and could name at least a few words that they claimed were present only in Weißkircherisch.
} 
Given the prolonged contact between TrSax, German, and Romanian, and the fact that most TrSax speakers are currently trilingual, structural transfer from German and/or Romanian into TrSax is a highly likely possibility (cf. Thomason 2010:40). However, some features of a language may be more prone to contact effects than others. Generally, features that are structurally detachable and semantically transparent tend to transfer more easily than features that are structurally and semantically bound in their domain, e.g., free morphemes transfer more readily than bound morphemes, as do derivational affixes when compared to inflectional affixes (Matras 2011: 208). The direction and the degree of transfer, however, are determined by the social contexts and the typological properties of the languages in contact (Thomason \& Kaufman 1988:19).

By surveilling two morphosyntactic features that are currently in variation in TrSax, and analyzing these features based on data provided by TrSax speakers with different levels of use and exposure to German and Romanian, I am able to determine how different morphosyntactic subsystems of the language respond to contact effects from the two languages. At the same time, data from such speakers can further our understanding of the types of structures that tend to remain unaffected by contact effects. Within each community, social contexts remain constant, thus allowing me to establish if both subsystems of Viscri Saxon are prone to the same contact effects, i.e. if they are both changing in the same direction under the influence of a contact language, or whether they react differently based on their structural properties.

I identified two areas of TrSax grammar that display variation and in each case one of the variants has a structural correspondent in German and the other variant has a structural correspondent in Romanian. Both of these areas may be prone to contact effects from both contact languages, as recent studies have shown that overlapping structures are a vulnerable locus for cross-linguistic transfer (Baptista et al. 2014, Jacob et al. 2017). The first variable is word order in two-verb clusters, i.e. constructions that consist of a finite (FIN) auxiliary/modal and a nonfinite verb $(\mathrm{V})^{3}$ that are strictly adjacent and occur in the right periphery of a subordinate clause (cf. Wurmbrand 2017). The verb clusters I am discussing hereafter pertain to subordinate clauses only (unless otherwise mentioned), regardless of the language they belong to. Both V-FIN and FIN-V orders can be encountered in TrSax as shown in examples (1) and (2) below.

$\operatorname{TrSax}$ (Viscri Saxon dialect)

wot de Guoiss-malsch

that the goat-milk have.3PL.PRS

(There were families) that drank the goat milk.

$\begin{array}{llll}\text { datt se } \quad \text { Wasser } & \text { ge-dreank-enV } & \text { hat } \\ \text { that she water } & \text { PCPT-drink-PCPT } & \text { have.3SG.PRS } \\ \text { '(It was her bad luck) that she drank the water.' }\end{array}$

German allows only for V-FIN order in subordinate clauses, while Romanian allows only for FIN-V order, thus TrSax is structurally distinct from both German and Romanian in this respect. TrSax speakers in my study report that FIN-V is the 'native' TrSax order and V-FIN is borrowed from German. Previous studies support this anecdotal evidence (see Holzträger 1912, and Bancu 2019a for a more detailed account), and attribute the V-FIN order to German influences.

Word-order variation in West-Germanic verb clusters is quite common, and it is typically attributed to linguistic factors. For example, Luxembourgish (closely related to TrSax) allows

\footnotetext{
${ }^{3}$ In TrSax and other Germanic languages, when an auxiliary is part of a two-verb cluster, the non-finite verb is a participle. When a modal is present in such a cluster, the non-finite verb is an infinitive.
} 
both the V-FIN and the FIN-V order in auxiliary + V constructions, but requires the FIN-V order in modal $+\mathrm{V}$ constructions (Bruch 1973: 92-94). West Flemish (also related to TrSax) allows VFIN order only in auxiliary $+\mathrm{V}$ constructions and FIN-V order only in modal $+\mathrm{V}$ constructions (Wurmbrand 2017:10). Another variety related to TrSax, Moselle Franconian, allows both the VFIN and the FIN-V orders in auxiliary $+\mathrm{V}$ and in modal $+\mathrm{V}$ constructions, though V-FIN order is overall more frequent (Dubenion-Smith 2008:147). Thus, it remains to be established if the presence of an auxiliary or a modal in a verb cluster has an effect on word order in $\operatorname{TrSax}$ to the same extent it does in related varieties.

The second variable targeted in this study is conjunction choice between two coordinating conjunctions, end and och, that fulfill the grammatical function of 'and', as shown in (3) and (4) below. Both conjunctions are used to conjoin finite clauses (TP) in these examples.

TrSax (Viscri Saxon dialect)

$\begin{array}{ll}\text { [et } & \text { wa } \\ \text { it } & \text { be. } \\ \text { end } & {[\mathrm{ka}} \\ \text { and } & \text { can }\end{array}$

waus

be.3SG.PST

and can.3SG.PST

uständlich $]_{\mathrm{TP}}$
inconvenient
niet moihr
not more

wunni

when go.INF

'It was inconvenient and one could not go (there) all the time.'

(4)

$\begin{array}{lllll}\text { [mer } & \text { zahn } & \text { af de } & \text { Fosnecht }]_{\mathrm{TP}} & \\ \text { we } & \text { move.3PL.PST } & \text { on the.F.SG.DAT } & \text { carnival } & \\ \text { och } & \text { nei } \quad \text { ea.m } & \text { Harwest seull-en } & \text { mer af de } & \text { Hochzetj }]_{\mathrm{TP}} \\ \text { and } & \text { now in.DAT } & \text { fall shall-3PL.PRS } & \text { we on the.F.SG.DAT wedding }\end{array}$

The examples shown above suggest that end and och can be used interchangeably in similar contexts, but the extent to which this is possible will be further explored in this paper. However, previous mentions of conjunctions in existing work on TrSax, and an analysis of these two conjunctions in a TrSax corpus collected the 1960s indicate that end is used to conjoin finite clauses, and $o c h$ is used to conjoin determiner and adjective phrases, as well as non-finite verbs (Kisch 1900, McClure 1973, Shinohara 2016). Therefore, the type of coordinands, i.e. the units that are coordinated by a conjunction (Haspelmath 2007), might have an effect on conjunction choice in this case.

Contact effects from German and/or Romanian might affect how these conjunctions are used in light of intensified contact between TrSax and German, and TrSax and Romanian. German has only one coordinating conjunction, und 'and', a cognate of end. Romanian has the coordinating conjunction și 'and' that also functions as the additive particle 'also'. In this respect, TrSax and Romanian are similar because TrSax och can be used with the function of 'also' as well. Thus, German-dominant speakers might show a preference for end, while Romanian dominant speakers might show a preference for och.

I follow Matras' $(2007,2011)$ view on transfer ${ }^{4}$, according to which structural transfer involves speakers renouncing the separation between two subcomponents of their linguistic repertoire and using the same structures across their languages. This implies that such structures would pattern similarly in both the donor and the recipient language. If variation in TrSax is the result of transfer from German and/or Romanian, I expect that linguistic factors will not have

\footnotetext{
${ }^{4}$ Matras $(2007,2011)$ uses the term 'borrowing' in his definition. I prefer the term transfer due to its more neutral nature (cf. Heine \& Kuteva 2005) to refer to linguistic features (e.g., lexical, phonological, morphologic, syntactic, semantic) that are incorporated from a donor language into a receiving language.
} 
much of an effect on variation, because each of the languages in contact with TrSax do not display variation in either of the areas that do so in TrSax. In other words, word order in verb clusters in German and Romanian ${ }^{5}$ is fixed and does not depend on whether an auxiliary or a modal is present in a construction. Similarly, because both German and Romanian have only one coordinating conjunction corresponding to 'and', these conjunctions can be used with any type of coordinand.

The descriptions I provided so far for the two areas of TrSax morphosyntax that display variation (verb clusters and coordinating conjunctions), and for the corresponding structures in German and Romanian (the languages in contact with TrSax) are summarized in Table 1.

\begin{tabular}{cccc}
\multirow{2}{*}{ LANGUAGE } & $\begin{array}{c}\text { WORD ORDERS IN } \\
\text { VERB CLUSTERS }\end{array}$ & $\begin{array}{c}\text { COORDINATING } \\
\text { CONJUNCTIONS }\end{array}$ & $\begin{array}{c}\text { ADDITIVE } \\
\text { PARTICLES }\end{array}$ \\
\hline TrSax & V-FIN/FIN-V & end/och & och \\
Standard German & V-FIN & und & auch \\
Romanian & FIN-V & și & și \\
\hline
\end{tabular}

Table 1. Target structures in TrSax and their corresponding structures in German and Romanian

The first step in each case study is to determine whether the structural correspondences between TrSax and German and TrSax and Romanian are the result of transfer, i.e. whether variation is between inherent TrSax forms and transferred forms. For example, studies on contact-induced language change suggest that structures that are similar between the languages of a bilingual are most prone to contact effects (cf. Baptista et al. 2014, Jacob et al. 2017), and such effects could occur in the way frequency distributions of forms that are in variation are affected. Variants that are similar in the recipient language and the contact language may become the preferred forms in the recipient language (Fernández et al. 2017). Based on these assumptions, I expect German-dominant speakers of TrSax to show a preference for German-like structures and Romanian-dominant speakers to show a preference for Romanian-like constructions in both areas that display variation in TrSax, if variation is indeed the result of transfer.

2. Identifying sources of variation in TrSax. There are several challenges I encountered in analyzing variation and language change in TrSax, and I designed this study in response to such challenges. First, comparing current data to older data (i.e. a real time study) in order to track potential language changes is close to impossible, because diachronic data is scarce (TrSax has been transmitted orally over the centuries). The same holds for comparing a non-contact variety of TrSax to a contact variety in order to identify contact-induced changes (cf. Thomason 2001:93-94), because TrSax has always been in contact with German and Romanian.

A second challenge in analyzing the structure of TrSax comes from the fact that there are about 240 different dialects of TrSax that are currently spoken to different degrees in Romania and Germany. These dialects correspond to the different localities where TrSax has been historically spoken in Romania and they can be distinguished through phonological, lexical and/or

\footnotetext{
${ }^{5}$ Romanian is not a verb-clustering language, but it could still serve as a source of transfer. FIN-V constructions in Romanian have shared properties with verb clusters: the FIN and the verb are strictly adjacent and cannot be separated by other elements, a property that Romanian shares with Germanic languages and not with other Romance languages (Monachesi 2005:138).
} 
morpho-syntactic characteristics ${ }^{6}$. Synchronic data collected in the 1960 s is available for about 140 different TrSax dialects primarily in the form of Wenker sentences ${ }^{7}$ through an audio-atlas (the ASD) ${ }^{8}$. A comparison of synchronic data from these regionally well-distributed dialects can help identify target features that are native to TrSax if sufficient examples are available to show that such features are shared by all dialects.

The dialects are distributed over three main areas in Transylvania as indicated in Figure 1 below: the grey shaded region on the map indicates where Transylvania is located in Romania, while the red dots show one dialectal area in the north and two separate areas in the south of Transylvania. These areas correspond to the original regions where Transylvanian Saxons settled when they came to Romania in the $12^{\text {th }}$ century AD.

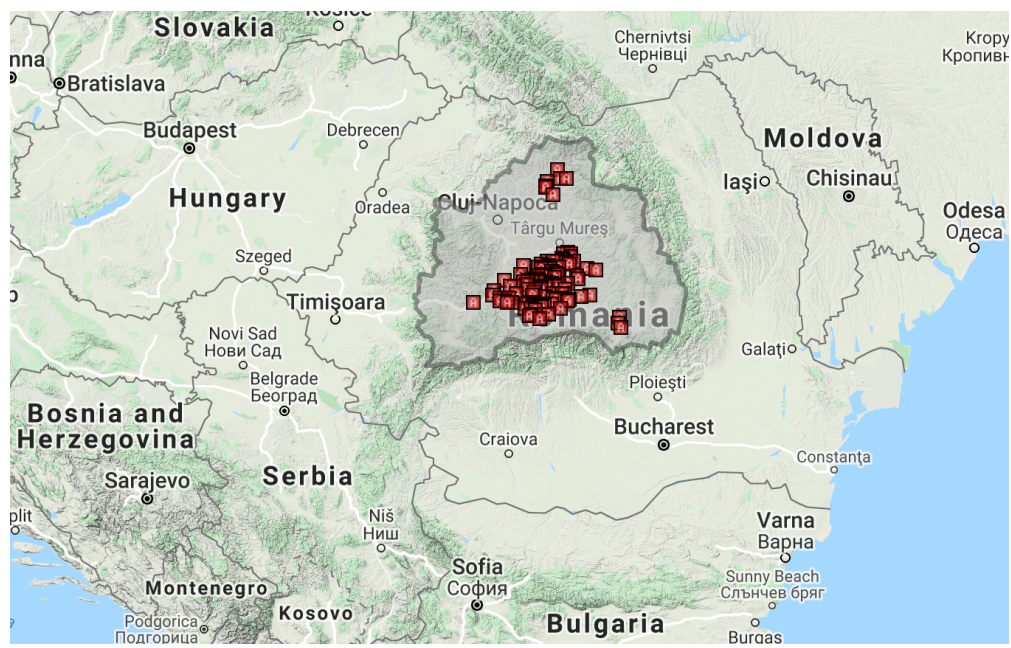

Figure 1. Transylvanian Saxon dialectal areas (Source: ASD)

There are sufficient examples of sentences that contain conjunctions in the ASD corpus, but a similar analysis is not possible for verb clusters. There are 12 Wenker sentences with conjunctions in the ASD corpus, and elicited examples for each sentence are available from about 120 different dialects. I used these examples to establish exactly what type of coordinands occur with each conjunction (e.g., finite clauses, NPs, PPs, APs, etc.), and to formulate some generalizations for TrSax based on a considerable number of dialects. For each Wenker sentence that contained conjunctions, I established what types of coordinands were conjoined, counted how often end and och occurred, and calculated proportions based on the token counts for end and for och for each target sentence ${ }^{9}$. I identified three types of patterns based on the types of coordinands that occurred with each conjunction in the data: conjunction of two finite clauses (TP) overwhelmingly realized with end, conjunction of a finite clause (TP) and a clause with an unexpressed finite verb $\left(\mathrm{TP}_{(-\mathrm{FIN})}\right)$ typically realized with och, and conjunction of phrases such as DPs and APs

\footnotetext{
${ }^{6}$ It is therefore important to mention that the results I present in this article pertain to Viscri Saxon, and examples from different dialects will be labeled throughout the article.

${ }^{7}$ Wenker sentences are a set of 42 sentences, designed by William Wenker in 1880 with the purpose of capturing differences among German dialects.

${ }^{8}$ ASD - Audioatlas Siebenbürgisch-Sächsicher Dialekte 'The Audio-Atlas of Transylvanian Saxon dialects' hosted by the Ludwig Maximillian University of Munich, Germany, available at http://www.asd.gwi.uni-muenchen.de/.

${ }^{9}$ A similar analysis can be found in Shinohara (2016). We have different views on the properties of these conjunctions. Shinohara analyzes och as an adverb that functions as a conjunction; I consider end and $o c h$ to be categoryspecific conjunctions in TrSax. I replicated part of her analysis to ensure that the correct target tokens were selected.
} 
overwhelmingly realized with $o c h$. The extent to which end and och occur with different types of coordinands based on these generalizations is represented in Table 2 below.

\begin{tabular}{cccc} 
COORDINANDS & END & OCH & TOKENS \\
\hline TP \& TP & $97 \%$ & $3 \%$ & 857 \\
TP \& TP (-FIN) & $34 \%$ & $66 \%$ & 290 \\
DP \& DP & $17 \%$ & $83 \%$ & 605 \\
AP \& AP & $10 \%$ & $90 \%$ & 41 \\
\hline
\end{tabular}

Table 2. Results of Wenker sentence analysis by type of coordinand

A few clarifications are in order. What distinguishes a TP from a $\mathrm{TP}_{(-\mathrm{FIN})}$ is that the latter does not have an expressed finite auxiliary or modal, such as in (5) below, where the modal messt 'must' is only expressed in the first clause and elided in the second clause:

Mortesdorf Saxon (Source: ASD|Mortesdorf|210|WS16) ${ }^{10}$

$\begin{array}{lllll}\text { (5) }[\text { te } & \text { MESST } & \text { nech ea } & \text { wenich } & \text { weochsen }]_{\mathrm{TP}} \\ \text { you.2SG } & \text { must.2SG.PRS } & \text { more a } & \text { brow.INF } \\ \text { [och } & \text { MESST } & \text { gresser worden }]_{\mathrm{TP}(-\mathrm{FIN})} & \\ \text { and } & \text { must.2SG.PRS } & \text { bigger become } & \\ \text { 'You MUST } & \text { grow a bit more and MUST become bigger. } & \end{array}$

Subject ellipsis is common in the analyzed Wenker sentences, and it does not seem to influence conjunction choice, but ellipsis of the finite verb does.

The patterns shown in Table 2 above indicate that each conjunction strongly favors a specific type of coordinand, thus exhibiting a behavior commonly attributed to category-specific conjunctions (cf. Haspelmath 2004, 2007). While European languages do not have category-specific conjunctions, such conjunctions are typical in cases of intense language contact, such as in the case of creole languages (see Baptista 2002, Holm \& Patrick 2007 for examples). Thus, contact between TrSax and Romanian could be a plausible explanation for why TrSax has developed two conjunctions, given that other Germanic languages have only one conjunction. Romanian has the conjunction și 'and' and the additive particle și 'also'. Similarly, TrSax has the conjunction och 'and' and the additive particle och 'also'. This structural similarity between TrSax and Romanian could be attributed to transfer from Romanian into TrSax. However, the fact that the conjunction och is used with the same types of coordinands across several TrSax dialects that are well distributed regionally, leads me to believe that category-specific conjunctions have been present in TrSax from the initial stages of its formation. These conjunctions are not a recent development that could be attributed to more intensified contact with Romanian, as the patterns shown in Table 2 are well established and diffused among many TrSax dialects. For such a change to occur and become established in a target language under the influence of a contact language, a prolonged intense contact for several centuries seems to be necessary (Backus et al. 2011). ${ }^{11}$

Given that TrSax dialects evolved over the centuries through oral transmission, I am proposing that morphosyntactic features and patterns of variation that are similar across dialects that have been in relative geographic isolation from each other are possibly inherent to TrSax. The

\footnotetext{
${ }^{10}$ This example comes from the ASD corpus. I am following the citation convention recommended by the ASD in indicating the source.

${ }^{11}$ For space considerations I will not try to account for the development of category-specific conjunctions in $\operatorname{TrSax}$ here, but several explanations are available in Bancu (2019b).
} 
nature of this elicited data restricts the possibilities for which aspects of TrSax morphosyntax can be analyzed. However, data collected from TrSax speakers in Germany and in Romania fills these gaps. Comparing data from a high-contact variety of a target language to data from a lowcontact variety has the potential to provide a clearer account of the effects contact languages can have on a target language (cf. Fernández et al. 2017, Kootstra \& Şahin 2018), but also shed light on features that remain stable in contact situations. More explicitly, by comparing data from TrSax speakers in Germany to data from TrSax speakers in Romania can help identify features that are different between the two TrSax varieties, and assess whether such features can be attributed to potential contact effects from German and Romanian. The following section elaborates further on how this can be done by using factors that account for a speaker's multilingual profile in sociolinguistic analyses of variation.

3. Data, participants, methodology. The data analyzed in the two case studies were collected in Viscri, Romania and in the Nuremberg area in Germany. All participants are originally from Viscri, Romania, and speak a dialect of TrSax that they identify as Weißkircherisch 'Viscri Saxon'. Seven Viscri Saxon speakers (5 female, 2 male) ages 30 - 78 were recorded in Romania and 7 speakers ( 4 female, 3 male) ages 30 - 75 were recorded in Germany using a sociolinguistic interview technique (cf. Tagliamonte 2006). All participants had acquired Viscri Saxon from birth and (with the exception of one) were able to have a fluent conversation in German and Romanian as well. The Viscri Saxon speakers recruited in Germany had lived there for at least 25 years.

Participants also filled out the Bilingual Language Profile (BLP) questionnaire (Birdsong et al. 2012). The BLP is set up to calculate a global language dominance score for each language by weighing in module scores for language history, language use, language proficiency, and language attitudes towards each language of a bilingual. The global scores were used to assess participants' language dominance in German and Romanian, and the background information collected through the questionnaire was used to better understand how the two groups differed in terms of sociolinguistic backgrounds.

Additional information about the participants' sociolinguistic background is provided in Table 3, below. The numbers for each participant group represent averages (SD indicates the standard deviation). Significant differences between the two groups are indicated with an asterisk in the first column and the differences were calculated using t-tests in R.

\begin{tabular}{lcccc} 
& $\begin{array}{c}\text { ROMANIA } \\
\text { PARTICIPANTS }\end{array}$ & SD & $\begin{array}{c}\text { GERMANY } \\
\text { PARTICIPANTS }\end{array}$ & SD \\
\hline Age & 53 & 15.59 & 53.7 & 14.6 \\
Age of Acquisition German & 9.14 & 11.52 & 5 & 2 \\
Age of Acquisition Romanian & 6.14 & 2.85 & 9.71 & 8.99 \\
Years spent in Romania* & 50 & 18.08 & 24.57 & 11.60 \\
Years spent in Germany* & 3 & 4.58 & 29.14 & 3.76 \\
Dominance score: German* & 128.5 & 35.63 & 167.72 & 20.83 \\
Dominance score: Romanian* & 147.45 & 29.26 & 103.20 & 14.08 \\
Dominance score: TrSax & 144.61 & 21.06 & 135.07 & 15.95 \\
\hline
\end{tabular}

Table 3. Characteristics of the participants

The two groups are very cohesive in terms of age and age of acquisition of the different languages they speak. Participants in Germany spent significantly more time in Germany than participants in Romania $(t=-11.67, p<0.001)$, and significantly less time in Romania as 
compared to participants who reside in Romania $(t=3.13, p=0.01)$. The last three rows in Table 3 represent the average language dominance scores for each language. The higher the average score is for a given language, the more dominant the group is in the respective language. Participants in Germany have significantly higher dominance scores for German and significantly lower dominance scores for Romanian than participants in Romania. However, there is no difference between the groups in terms of dominance for TrSax.

For each analysis of variation, I used mixed effects models (glmer package in R) to test the effect of social and linguistic factors on variation. The language dominance scores for German and Romanian were included as a continuous variable in the models as they were considered to be one of the main predictors for contact effects in both case studies. Because the language dominance scores already contain information about a participant's history, i.e. about age, age of acquisition of the different languages, time spent in a region where the language was spoken, these variables were not included separately in the models. The individual speaker was included as a random effect in each model, so that any speaker whose performance is dissimilar from the other speakers will not skew the distribution.

The transcribed interviews were used to detect all subordinate clauses that contained twoverb clusters and were introduced by a subordinating conjunction or a relative pronoun. This resulted in 395 tokens. The presence of an auxiliary or a modal in a cluster was coded for each token. For conjunctions, 30 tokens were selected for each conjunction for each participant. The selection started at about 10 minutes into the recording and continued until the target number was reached. The types of coordinands that preceded and followed each conjunction were coded for each token. Two of the participants did not deliver 30 examples for each conjunction (even after searching through the entire transcript), thus a total of 814 tokens were analyzed for conjunction choice.

\section{Results}

4.1. WORD ORDER IN VERB CLUSTERS.. Both FIN-V and V-FIN word orders were encountered in verb clusters and were used by participants in both groups. In the data from the participants in Romania, $49 \%$ of all subordinate clauses with verb clusters contained the FIN-V order and $51 \%$ contained the V-FIN order (based on 188 tokens). The FIN-V order occurred in $28 \%$ of the examples provided by participants in Germany, and the V-FIN order occurred in $72 \%$ of the examples (based on 207 tokens). Whether these differences are significant will be further explored in a generalized mixed linear model with word order as a dependent variable, type of construction (Aux or M), Site (Romania or Germany), and dominance scores as fixed effects, and the individual speaker as a random effect. The results of the generalized mixed effects model (glmer) are shown in Table 4 below:

\begin{tabular}{ccccc} 
FiXeD EFFECTS & ESTIMATE & SE & Z VALUE & $\boldsymbol{P}$ VALUE \\
\hline \hline (Intercept) & -0.293 & 0.503 & -0.582 & 0.561 \\
Aux or M & 0.808 & 0.288 & 2.807 & 0.005 \\
Site (R) & -0.525 & 0.576 & -0.911 & 0.362 \\
Dominance & -0.025 & 0.005 & -4.569 & 0.000005 \\
\hline Random Effect: Speaker & Variance: 0.438 & Std. deviation: 0.662 \\
$\mathrm{~N}=395$, Speakers $=14$ & & & \\
\hline
\end{tabular}

Table 4. Results of generalized linear mixed effects model for word order in verb clusters 
The results in Table 4 show that the type of construction has a significant effect on word order. Across the two groups, the FIN-V order is more likely to occur when the FIN is an auxiliary rather than a modal $(p<0.01)$. Note that this trend is different from what is typical for related Germanic languages such as Luxembourgish or Flemish, where the FIN-V order is preferred or required with modal verbs. Language dominance also has a significantly strong effect $(p<0.001)$ on word order: a decrease in language dominance score, which corresponds to less German dominance and conversely more Romanian dominance, increases the odds for the FIN-V order. Speakers who are more German-dominant are more likely to use German-like order (V-FIN) than speakers who are more Romanian-dominant. The latter are more likely to use Romanianlike order (FIN-V). The site (reference is set to Romania in the glmer output) does not have an effect on word order in this model, but there is a significant correlation between the dominance scores and site (Pearson's $r=0.615$ ), i.e. the higher dominance scores are (more German dominant), the more likely it is that participants are in Germany. An additional model that I ran without the dominance scores showed that the site had a significant effect on word-order: speakers in Romania are more likely to use the FIN-V order than speakers in Germany $(p=0.045)$. Conversely, speakers in Germany are more likely to use the V-FIN order.

There are noticeable differences in how individual participants use each construction. Figure 2 below gives an overview of how the available constructions pattern among the individual speakers and shows the language dominance scores under the label for each participant. Speakers in Germany are labeled with GE and speakers in Romania are labeled with RO. The youngest speaker in each group is indexed with 1, while the oldest speaker in each group is indexed with 7. The language dominance scores are calculated as the difference between the score obtained for German and the score obtained for Romanian. Scores that are close to 0 would indicate a balanced language dominance, scores that are higher than 0 indicate German-dominance, while negative scores indicate Romanian-dominance.

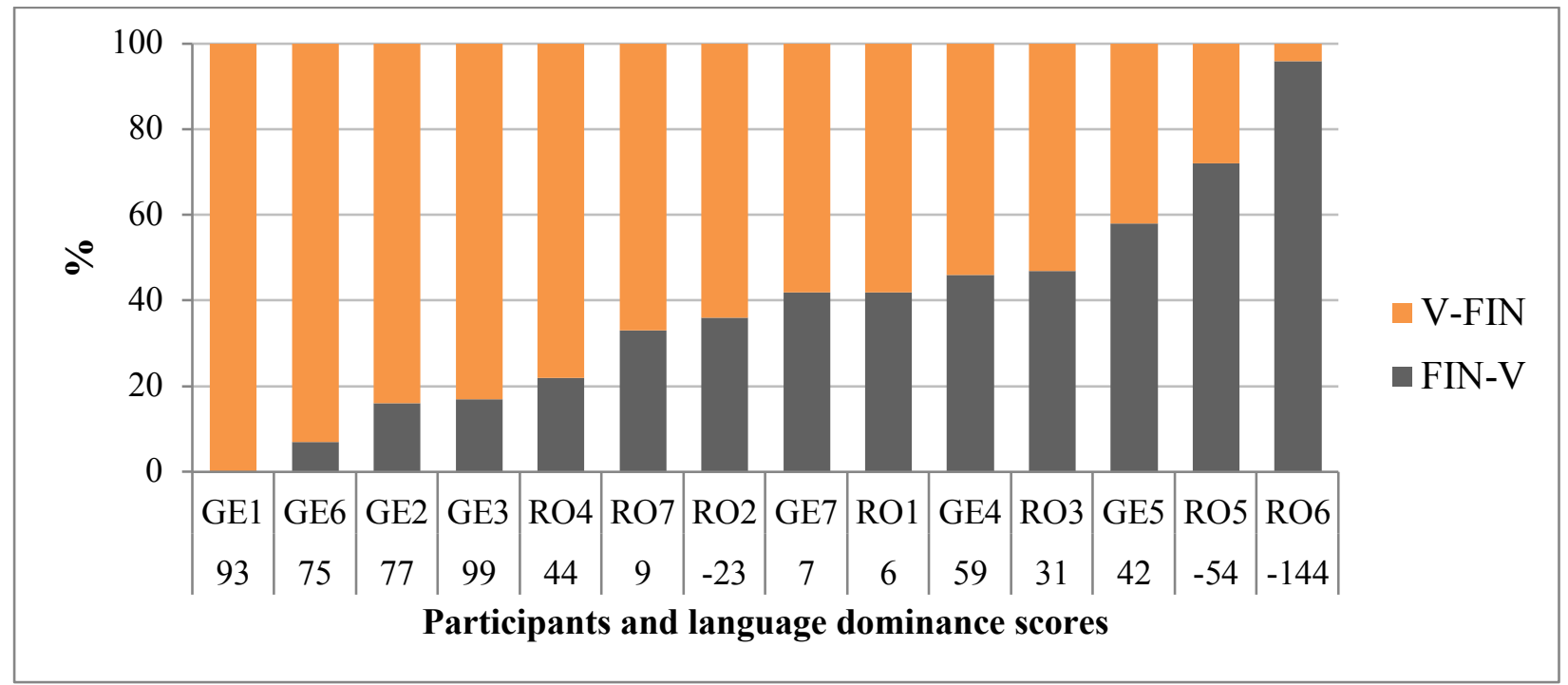

Figure 2. Combined word order distribution among all participants and dominance scores

A broad generalization can be made when combining the different distributions of word orders across speakers from both groups. It appears that speakers with positive scores over 70 use the V-FIN order in more than $80 \%$ of their utterances, while speakers with high negative scores (over 50) use the FIN-V order in more than $70 \%$ of their utterances. This broad distribution of 
the two word orders, ranging from exclusive use of FIN-V to almost exclusive use of V-FIN indicates that language dominance is the main predictor for word-order variation, and that variation is not constrained by linguistic factors, even though FIN-V order is preferred when an auxiliary is present in a construction.

4.2. CONJUNCTION CHOiCE. The results presented in this section relate to Viscri Saxon data only. A total of 814 utterances and phrases containing coordinating conjunctions were analyzed (398 tokens from Romania-participants, 416 tokens from Germany-participants), 409 tokens for end and 405 tokens for $o c h$. When the coordinands to the left and right of a conjunction were both determiner phrases (DP, 214 tokens), both adjective and adverb phrases (AP, 32 tokens), and both prepositional phrases (PP, 24 tokens), the conjunction och was used $99.8 \%$ of the times. When a main tensed clause (TP) was conjoined with a clause with an unexpressed finite verb (TP-FIN), och was used 97.5\% (40 tokens). When the coordinands were two TPs, end was used $82 \%$ (494 tokens).

However, once the TPs were broken down further, it became evident that end was the preferred conjunction when two main clauses were conjoined ( $83 \%$ end, 17\% och, 424 tokens), but when two subordinate clauses were conjoined, och was used $95 \%$ of the times (32 tokens). In cases where the coordinands were not of the same type, i.e. a main clause and a subordinate clause, or a TP and a DP, end occurred in $67 \%$ of the examples and och in $33 \%$ of the examples (based on 38 tokens).

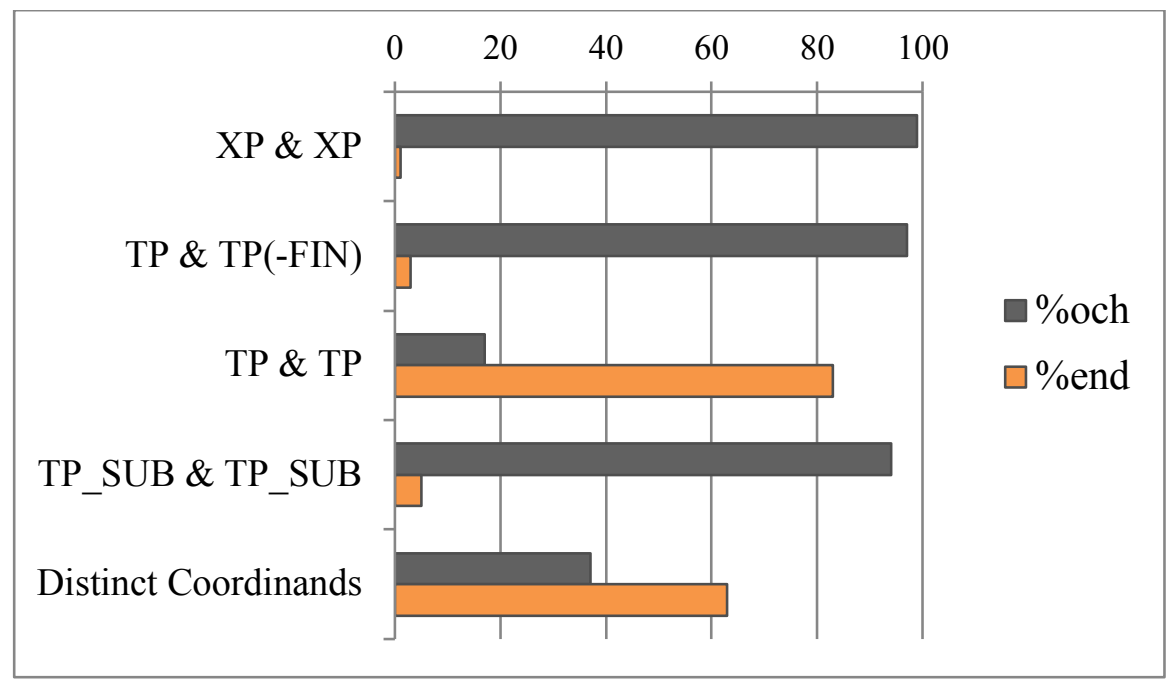

Figure 3. Conjunction choice by type of coordinand

Examples of distinct coordinands with each conjunction are given in (6) and(7) below. Subordinate clauses are shown in parentheses and main clauses are shown in square brackets. In (6), a subordinate clause is conjoined with a main clause with the conjunction end. Example (7) shows a subordinate clause conjoined with a main clause with $o c h$.

\section{Viscri Saxon}

$\begin{array}{llll}\text { wuarschenlich gluiwen } & \text { de } & \text { et (wuat em ean } \\ \text { probably } & \text { believe.3PL.PRS they } & \text { it what them one } \\ \text { end [sen } & \text { zefrieden } & \text { der-meat] } & \\ \text { and be. 3PL.PRS content } & \text { there-with }\end{array}$

'They probably believe what they are being told and are content with it.' 


\begin{tabular}{|c|c|c|c|c|c|}
\hline $\begin{array}{l}\text { le Jaujer } \\
\text { the hunters }\end{array}$ & $\begin{array}{l}\text { hun es } \\
\text { have.3PL.PRSus }\end{array}$ & $\begin{array}{l}\text { ge-see-t } \\
\text { PCPT.tell. PCPT }\end{array}$ & $\begin{array}{l}\text { (datt } \\
\text { that }\end{array}$ & $\begin{array}{l}\text { Biear } \\
\text { bear }\end{array}$ & $\begin{array}{l}\text { git) } \\
\text { give.3SG.PRS }\end{array}$ \\
\hline e.PL & $\begin{array}{ll}\text { Hirte-n hu } & \text { hhepherd-PL ha }\end{array}$ & e.3PL.PRS & $\begin{array}{l}\text { se } \\
\text { them }\end{array}$ & $\begin{array}{l}\text { alduist } \\
\text { sometimes }\end{array}$ & $\begin{array}{l}\text { gesahn] } \\
\text { see.PCT }\end{array}$ \\
\hline
\end{tabular}

'The hunters told us that there were bears (in the area) and the shepherds have seen them occasionally.'

I ran a generalized mixed effects model that included the coordinands that occurred with both conjunctions (TP \& TP, asymmetrical coordinands) and the participants' dominance scores as fixed effects to determine whether there were any contact effects present for conjunction choice (dependent variable). The likelihood of using och to conjoin two main clauses (TP \& TP) is significantly lower than for using end, i.e. the preferred conjunction for conjoining two main clauses is end $(p<0.001)$. There was no effect of dominance scores $(p>0.05)$, or 'asymmetrical coordinands' on conjunction ( $\mathrm{p}>0.05$ for both factors).

The results of the analysis show that end has a category-specific function in Viscri Saxon, namely to conjoin finite TPs with expressed verbs, and och can be used everywhere else. The primary function of och is to conjoin phrases, clauses where finite auxiliary/modal ellipsis occurs in the second clause, and subordinate clauses. Och may be preferred to conjoin subordinate clauses because there is more symmetry and more semantic similarity between such clauses than between two main clauses, as two subordinate clauses form one constituent that is dependent on a main clause. Similarly, phrases that are conjoined by och form one constituent that is dependent on (or dominated by) another constituent. When two subordinate clauses are conjoined, they both entail information about the same main clause that they are subordinate to. Even more, the same subordinate conjunction can scope over two subordinate clauses, as in (8) below. The subordinate conjunction datt 'that' scopes over both subordinate clauses shown in parentheses below:

$$
\begin{array}{llll}
\text { ech sahn } & \text { datt } \quad[(\text { der } & \text { Zegun } & \text { kit) } \\
\text { I see.1SG.PRS } & \text { that the.M.SG } & \text { gypsy } & \text { come.3SG.PRS } \\
\text { och (ameraink } & \text { mohit)] } & & \\
\text { and around } & \text { mow.3SG.PRS } & & \\
\text { 'I see to it that the gypsy comes and mows all around (the premises).' }
\end{array}
$$

Och can be encountered (to a lesser extent than end) in all kinds of finite clauses as well, including clauses that are not syntactically similar, such as a main clause and a subordinate clause. There are thus indications that its function is not limited to conjoining phrases and it is extending to finite clauses. Over time it might compete with end for that domain, and, if Romanian has an effect on the distribution of the two conjunctions in this environment, och could become the preferred conjunction for combining two clauses. At this point in time, it is not a significant effect, as shown in the statistical analysis. Speakers may be well aware that och is a feature that is characteristic for TrSax and may find it more acceptable to use och to conjoin any types of coordinands, than to use end in such cases, because end is more German-like. The results of the analysis also show that there are no contact effects from German on the use of end. Such effects would be evident if the function of end would extend to conjoining all kinds of phrases, but such examples were minimal in the data.

5. Discussion and conclusions. The purpose of this study was to document and analyze structural variation in TrSax. In doing so I tried to establish whether German and/or Romanian, the languages in contact with TrSax, would have an effect on variation due to transfer phenomena. 
At the same time, I sought to determine whether different subsystems of TrSax morphosyntax would be affected to the same degree by the contact languages.

The first case study on word-order variation in two-verb clusters in subordinate clauses shows that language dominance has a significant effect on word-order choice and speakers who are German-dominant are more likely to use V-FIN order (German-like) than speakers who are Romanian-dominant. Furthermore, individual patterns of variation range from exclusive use of FIN-V to exclusive use of V-FIN order, indicating that there are no linguistic constraints on word-order variation in subordinate clauses and that the distribution of word orders is highly conditioned by speakers' language dominance in German and Romanian.

The second case study on coordinating conjunction choice shows that variation is conditioned primarily by linguistic factors in this case: end is used to conjoin tensed main clauses and this rule is invariable, while och is used to conjoin phrases (DP, PP, AP) and different types of clauses (tensed clauses, TP and $\mathrm{TP}_{(-\mathrm{FIN})}$, subordinate clauses). Even though both end and och can conjoin clauses, och is used only to a limited degree in those cases and language dominance does not have an effect on conjunction choice, contrary to what occurs with verb clusters. Due to the typological similarity between TrSax and German, and the cognate status of TrSax end and German und, I expected the use of end to become more common with coordinands that can be conjoined with und in German. Consequently, I expected a higher degree of contact effects from German in this area in light of the intensified contact between Viscri Saxon and German, and the degree of bilingualism among participants from Germany, but these expectations were not met. Overall the results of my analysis show that there are two coordinating conjunctions in Viscri Saxon, end and och, and they both fulfill the grammatical function of 'and'. The two conjunctions are category-specific, in that end is used to conjoin finite clauses and och is used everywhere else, including finite clauses. Variation between the two conjunctions is determined solely by grammatical factors, and participants from both groups use the conjunctions with their grammatical constraints.

Using a sociolinguistic variationist approach to analyze variation in two morphosyntactic subsystems of TrSax has proven to be an effective way for establishing what exactly drives variation in each case. The fact that contact effects were present in one area (i.e. verb clusters), but not the other (i.e. conjunction choice), informs us further about the role structural factors play in the potential outcomes of language contact. A possible explanation for the differential outcomes in terms of contact effects could be the frequency of occurrence of the two types of constructions. In general, two-verb clusters are less frequent in speech than conjunctions, because they are restricted to subordinate clauses. This became evident in the data analysis: when selecting tokens for verb clusters, there were participants who delivered less than 20 examples over the entire recording ${ }^{12}$. In contrast, identifying 30 tokens for each conjunction/participant was not challenging and this process only required about 20 - 30 minutes of recorded speech for the majority of the participants. The intensified contact between Viscri Saxon and German, and Viscri Saxon and Romanian over the past 25 years affected the frequency distributions of the two word orders in the case of verb clusters, and no linguistic constraints on word order could be detected. However, conjunctions are still operating by language internal rules. Because conjunctions occur more frequently than verb clusters, they might be more embedded in routine use and, thus, more resistant to contact effects (cf. Matras 2011, Thomason 2017).

12 Recordings lasted between $45 \mathrm{~min}-1$ hour. 


\section{References}

ASD. Audioatlas Siebenbürgisch-Sächsischer Dialekte (ASD). www.asd.gwi.unimuenchen.de. (last accessed 01.16.2020).

Backus, Ad, A. Seza Doğruöz \& Bernd Heine. 2011. Salient stages in contact-induced grammatical change: Evidence from synchronic vs. diachronic contact situations. Language Sciences 33(5). 738-752. https://doi.org/10.1016/j.langsci.2011.02.004.

Bancu, Ariana. 2019a. Contact-induced variation in Transylvanian Saxon verb clusters. Language 95(2). e193-e215. https://doi.org/10.1353/lan.2019.0041.

Bancu, Ariana. 2019b. Dynamics of language contact and language variation: The case of Transylvanian Saxon in the homeland and the eiaspora. Ann Arbor, MI: University of Michigan dissertation.

Baptista, Marlyse, Susan A. Gelman \& Erica Beck. 2014. Testing the role of convergence in language acquisition, with implications for creole genesis. International Journal of Bilin-gualism 20(3). 269-296. https://doi.org/10.1177/1367006914552459.

Baptista. Marlyse. 2002. The syntax of Cape Verdean creole: The Sotavento Varieties. Amsterdam: John Benjamins.

Birdsong, David, Libby M. Gertken \& Mark Amengual. 2012. Bilingual language profile: An easy-to-use instrument to assess bilingualism. COERLL, University of Texas at Austin.

Dubenion-Smith, Shannon A. 2008. Verbal complex phenomena in the West Central German dialects. Madison, WI: University of Wisconsin dissertation.

Fernández, Eva M., Ricardo Augusto De Souza \& Agustina Carando. 2017. Bilingual innovations: Experimental evidence offers clues regarding the psycholinguistics of language change. Bilingualism: Language and Cognition 20(2). 251-268. https://doi.org/10.1017/S1366728916000924.

Fishman, Joshua A. 1991. Reversing language shift: Theoretical and empirical foundations of assistance to threatened languages. Clevedon/Philadelphia: Multilingual Matters.

Haspelmath, Martin. 2004. Coordinating Constructions. An overview. In Martin Haspelmath (ed.), Coordinating constructions, 3-39. John Benjamins Publishing Company.

Haspelmath, Martin. 2007. Coordination. In Timothy Shopen (ed.), Language typology and syntactic description, 2nd Edition. 1-51. Cambridge, UK: Cambridge University Press.

Heine, Bernd; and Tania Kuteva. 2005. The Framework. In Bernd Heine \& Tania Kuteva (eds.), Language contact and grammatical change, 1-39. Cambridge: Cambridge University Press.

Holm, John \& Peter L. Patrick. 2007. Comparative Creole syntax. London: Battlebridge.

Holzträger, Fritz. 1912. Syntaktische Funktion der Wortformen im Nösnischen. Tübingen: Universität zu Tübingen dissertation.

Jacob, Gunnar, Kalliopi Katsika, Neiloufar Family \& Shanley E. M. Allen. The role of constituent order and level of embedding in cross-linguistic structural priming. Bilingualism: Language and Cognition 20(2). 269-282. https://doi.org/10.1017/S1366728916000717.

Kisch, Gustav. 1900. Nösner Wörter und Wendungen: Ein Beitrag zum siebenbürgisch-sächsischen Wörterbuch. Bistritz. Druck von Theodor Botschar.

Kootstra, Gerrit Jan \& Hülya Şahin. 2018. Crosslinguistic structural priming as a mechanism of contact-induced language change: Evidence from Papiamento-Dutch bilinguals in Aruba and the Netherlands. Language 94(4). 902-930. https://doi.org/10.1353/lan.2018.0050. 
Mansfield, John \& James Stanford. 2017. Documenting sociolinguistic variation in lesser-studied indigenous communities: Challenges and practical solutions. In Kristine A. Hildebrandt, Carmen Jany \& Wilson Silva (eds.), Documenting variation in endangered languages (Language Documentation \& Conservation Special Publication 13). 116-136. Honolulu: University of Hawai'i Press.

Matras, Yaron. 2007. The borrowability of structural categories. In Yaron Matras \& Jeanette Sakel (eds.), Grammatical borrowing in cross-linguistic perspective. 31-73 Berlin/New York: Mouton de Gruyter.

Matras, Yaron. 2011. Universals of structural borrowing. In Peter Siemund (ed.). Linguistic universals and language variation. 204-233. Berlin/New York: Walter de Gruyter.

McClure, Malcolm M. 1973. A grammar of the Weingartskirchen dialect of Transylvanian German. Berkeley, CA: University of California dissertation.

Meyerhoff, Miriam. 2019. Unnatural bedfellows? The sociolinguistic analysis of variation and language documentation. Journal of the Royal Society of New Zealand 49(2). 229-241. https://doi.org/10.1080/03036758.2019.1619599.

Monachesi, Paola. 2005. The verbal complex in Romance: A case study in grammatical interfaces. Oxford, UK: Oxford University Press.

Nagy, Naomi. 2017. Documenting variation in (endangered) heritage languages: How and why. In Kristine A. Hildebrandt, Carmen Jany \& Wilson Silva (eds.), Documenting variation in endangered languages (Language Documentation \& Conservation Special Publication 13). 33 - 64. Honolulu: University of Hawai'i Press.

O'Shannessy, Carmel. 2011. Language contact and change in endangered languages. In Peter Austin \& Julia Sallabank (eds.), The Cambridge handbook of endangered languages. 78-99. Cambridge, UK: Cambridge University Press.

Shinohara, Sara. 2016. Siebenbürgisch-Sächsisch als Kontaktsprache: Der konjunktionale Gebrauch von "auch" im Siebenbürgisch-Sächsischen. In Boris Blahak, Koloman Brenner, Ioan Lăzărescu, Jörg Meier \& Hermann Scheuringer (eds.), Forschungen zur Deutschen Sprache in Mittel-, Ost-und Südosteuropa FzDiMOS 6. 232-244.

Tagliamonte, Sali A. 2017. Perspectives on linguistic documentation from sociolinguistic research. In Kristine A. Hildebrandt, Carmen Jany \& Wilson Silva (eds.), Documenting variation in endangered languages (Language Documentation \& Conservation Special Publication 13). 6-32. Honolulu: University of Hawai'i Press.

Thomason, Sarah G. 2001. Language contact. Washington, D.C.: Georgetown University Press.

Thomason, Sarah G. 2010. Contact explanations in linguistics. In R. Hickey (ed.), The hand book of language contact. 31-47. Hoboken, NJ: Wiley-Blackwell.

Thomason, Sarah G. 2017. Contact as a Source of Language Change. In Brian D. Joseph \& Richard D. Janda (eds.), The handbook of historical linguistics. 687-712. Oxford, UK: Blackwell.

Thomason, Sarah G. \& Terry Kaufman. 1988. Language contact, Creolization, and Genetic linguistics. Berkeley: University of California Press.

Wurmbrand, Susi. 2017. Verb Clusters, Verb Raising, and Restructuring. In Martin Everaert \& Henk van Riemsdijk (eds.). The Blackwell companion to syntax. Second edition. 1-103. Hoboken, NJ: John Wiley \& Sons. https://doi.org/10.1002/9781118358733.wbsyncom103. 